\title{
The Impact Prediction Models of Neoplasia for Lung Nodules in High-Risk Patients
}

\author{
O Impacto dos Modelos de Predição de Câncer para Nódulos \\ Pulmonares em Pacientes de Alto Risco
}

Camilla Matos Pedreira ${ }^{1}$, José Alves Barros Filho ${ }^{2}$, Carolina Pereira ${ }^{3}$, Thamine Lessa Andrade $^{4}$, Ricardo Mingarini Terra ${ }^{5}$, Sergio Tadeu Lima Fortunato Pereira ${ }^{3}$, Gustavo Almeida Fortunato ${ }^{3}$

${ }^{1}$ Residente Cirurgia Geral Hospital Geral Ernesto Simões Filho; Salvador, Bahia; ${ }^{2}$ Residente Anestesiologia CET Integrado Vitória da Conquista; Vitória da Conquista, Bahia; ${ }^{3}$ Serviço de Cirurgia Torácica da Santa Casa de Misericódia da Bahia; Salvador, Bahia; ${ }^{4}$ Clínica AMO; Salvador, Bahia; ${ }^{5}$ Cirurgia Torácica da Faculdade de Medicina da Universidade de São Paulo; São Paulo, São Paulo, Brazil

Correspondence addresses: Camilla Matos Pedreira, MD camillapmatos@outlook.com

Received: August 16, 2019

Revised: August 28, 2019

Accepted: September 9, 2019

Published: September 27, 2019

Data Availability Statement: All relevant data are within the paper and its Supporting Information files.

Funding: This work was the result of author's initiative. There was no support of research or publication funds.

Competing interests: The author has declared that no competing interests exist.

Copyright

(C) 2019 by Santa Casa de Misericórdia da Bahia. All rights reserved. ISSN: 2526-5563
Objectives: This study aims to evaluate the impact of using three predictive models of lung nodule malignancy in a population of patients at high-risk for neoplasia according to previous analysis by physicians, as well as evaluate the clinical and radiological malignancy-predictors of the images. Material and Methods: This is a retrospective cohort study, with 135 patients, undergone surgical in the period from 01/07/2013 to 10/05/2016. The study included nodules with dimensions between $5 \mathrm{~mm}$ and $30 \mathrm{~mm}$, excluding multiple nodules, alveolar consolidation, pleural effusion, and lymph node enlargement. The main variables analyzed were age, sex, smoking history, extrathoracic cancer, diameter, location, and presence of spiculation. The calculation of the area under the ROC curve assessed the accuracy of each prediction model. Results: The study analyzed 135 individuals, of which $96(71.1 \%)$ had malignant nodules. The areas under the ROC curves for each prediction model were: Swensen 0.657; Brock 0.662; and Herder 0.633. The models Swensen, Brock, and Herder presented positive predictive values in high-risk patients, corresponding to $83.3 \%, 81.8 \%$, and $82.9 \%$, respectively. Patients with the intermediate and low-risk presented a high malignant nodule rate, ranging from $69.3-72.5 \%$ and $42.8-52.6 \%$, respectively. Conclusion: None of the three quantitative models analyzed in this study was considered satisfactory (AUC> 0.7) and should be used with caution after specialized evaluation to avoid underestimation of the risk of neoplasia. The pretest calculations might not contemplate other factors than those predicted in the regressions, that could present a role in the clinical decision of resection.

Keywords: Lung Nodules; Lung Cancer; Prediction Models.

Objetivo: Avaliar o impacto do uso de três modelos de predição de malignidade de nódulo pulmonar em uma população de pacientes considerados de alto risco para neoplasia de acordo com avaliação prévia de especialistas e avaliar preditores clínicos e radiológicos de malignidade da amostra. Material e Métodos: Estudo de coorte retrospectiva, incluindo 135 pacientes operados no período de 01/07/2013 a 05/10/2016. Foram incluídos nódulos com dimensões entre 5-30mm e excluídos aqueles com múltiplos nódulos, consolidação alveolar, derrame pleural e linfonodomegalias. Idade, sexo, história tabágica, relato de câncer extratorácico, diâmetro, localização e 
presença de espículas do nódulo foram as principais variáveis analisadas. A precisão de cada modelo de predição foi avaliada através do cálculo da área sob a curva ROC. Resultados: Foram analisados 135 indivíduos, dos quais $96(71,1 \%)$ apresentaram nódulos malignos. As áreas sob as curvas ROC para cada modelo de predição foram: Swensen 0,657; Brock 0,642 e Herder 0,633. Os modelos Swensen, Brock e Herder apresentaram valor preditivo positivo em pacientes de alto risco, correspondendo a $83,3 \%, 81,8 \%$ e $82,9 \%$, respectivamente. Os pacientes com riscos intermediário e baixo apresentaram uma elevada taxa de nódulo maligno, variando de 69,3-72,5\% e 42,8$52,6 \%$, respectivamente. Conclusão: Nenhum dos três modelos quantitativos analisados nesse estudo obteve uma acurácia considerada satisfatória (AUC $>0,7)$ e devem ser utilizados com cautela após avaliação especializada por subestimarem risco de neoplasia. Fatores outros, além dos previstos nas regressões, que apresentam papel na decisão clínica de ressecção, podem não ser contemplados pelos cálculos pré-teste.

Palavras-chave: Nódulos de Pulmão; Câncer de Pulmão; Modelos de Predição.

\section{Introduction}

Lung cancer is a highly lethal disease. In Brazil, it represents the majority of cancer-death cases in men, and it is the second more deadly cancer among women, with an estimate of 28,000 cases between 2016 and 2017. Despite all advances in diagnosis, staging, and treatment, five-year survival rates are still low. Most patients have an incurable disease at diagnosis due to locally advanced disease or distant metastases.

In recent years, the development of systematic lung cancer tracking protocols, as well as the more regular use of coronary tomography, have contributed to the more frequent incidental diagnosis of pulmonary nodules. So, the old models of prediction of malignancy have been reviewed and confronted with the modern multidisciplinary clinical judgment.

Researchers developed one of the most popular and widely cited models for pulmonary nodule patients at the Mayo Clinic (Swensen and colleagues - 1997 - a retrospective analysis of medical records and chest radiographs of 419 patients with a recent diagnosis of pulmonary nodules, between $4 \mathrm{~mm}$ and $30 \mathrm{~mm}$ from 1984 to 1986). According Swensen and colleagues, the following variables were considered as predictors of malignancy: age, smoking, history of extrathoracic neoplasia (at least 5 years), nodule diameter, upper lobe location, and presence of spicules. ${ }^{1,2}$

In 2007, Michael Gould and colleagues, ${ }^{1}$ from the Department of Veterans Affairs (VA), developed a model that considered four predictors of malignancy: age, smoking, cigarette abstinence time, and nodule diameter. This model has not been validated in non-smokers. ${ }^{1,3}$

In 2013, McWilliams and colleagues ${ }^{4,5}$ worked on separate regression (Brock University) that takes into account nine predictors of malignancy: age, gender, family history of lung cancer, emphysema, size, number and attenuation of the nodules, location in upper lobe and presence of spicules.

The model developed by Herder and colleagues $^{6}$ was an external validation of the model developed by Swensen, adding one more predictor: the uptake intensity of 18 F-fluorine deoxy-2-glucose (FDG) on PET scan.

A national study led by Cromwell and colleagues $^{7}$ in São Paulo has validated and compared the two mathematical models developed by Swensen and colleagues, and Gould and colleagues by retrospective analysis of 110 patients who underwent pulmonary nodule resection. In this study, the model developed by Swensen and colleagues ${ }^{2}$ showed a satisfactory result, demonstrating an area under the regular ROC curve; however, the model created by Gould and colleagues ${ }^{1}$ showed a lower result.

Despite the use of pretest calculations to support the decision making of pulmonary nodules, many current decisions are based on analyzes of clinical and radiological factors not covered by these models' calculations. It is ubiquitous for patients to be referred for invasive diagnostic procedures without previous calculation of the malignancy risks. The use of prediction models to improve the selection of patients for surgical biopsy has not been studied. Therefore, this study was designed to retrospectively assess 
the impact of these calculations on decisions in which patients were referred for surgery after multidisciplinary clinical judgment.

\section{Material and Methods}

\section{Type of Study}

This is a retrospective, observational cohort study with 135 patients with suspected pulmonary nodule by $\mathrm{CT}$, who obtained surgical indication after a discussion by a multidisciplinary team.

Population

Patients accompanied during appointments and operated by a single thoracic surgery team (CIRTORAX), from July $1^{\text {st }}, 2013$ to October $5^{\text {th }}$, 2016, in the city of Salvador, Bahia, Brazil.

\section{Inclusion Criteria}

- Nodules between $5 \mathrm{~mm}$ and $30 \mathrm{~mm}$;

- Solid or partially solid ground glass nodules;

- Nodules that had a surgical indication for resection after multidisciplinary clinical judgment due to suspected neoplasia.

\section{Exclusion Criteria}

- Multiple nodes (more than 5 besides the main);

- Metastatic disease;

- Presence of consolidation, pleural effusion, and CT lymph node enlargement;

- Incomplete clinical data.

Data

Clinical data were obtained from the surgical electronic medical records, and compiled in an Excel 2016 table, and exported to the SPSS 20.0 software for statistical analysis. The probability of nodule malignancy was calculated based on three prediction models applied to all patients (Swensen and colleagues, ${ }^{2}$ Brock University, ${ }^{5}$ and Herder and colleagues $\left.{ }^{6}\right)$. The model developed by Herder and colleagues ${ }^{6}$ used a FDG-18F nodule avidity scale based on the classification proposed by AlAmari and colleagues: ${ }^{8}$ no uptake, poor uptake (SUV <2.6); moderate uptake (SUV between 2.6-10) and intense uptake (SUV> 10). ${ }^{8}$ Based on these prediction scores / models, patients were classified into the three groups: low-risk (less than $5 \%$ ); intermediate-risk (between 5\%-65\%) and high-risk ( $>65 \%) .{ }^{9}$ All diagnoses had histological confirmation.

\section{Study Variables}

The clinical data considered in this study were the predictors of malignancy from the three models:

1. Swensen and colleagues: ${ }^{2}$ patient age, smoking history, history of extrathoracic cancer, nodule diameter, upper lobe location, borders, and presence of spicules.

2. Brock University: ${ }^{5}$ age, sex, family history of lung cancer, presence of emphysema, nodule size, nodule attenuation, upper lobe location, number of nodules, borders, and presence of spicules.

3. Herder and colleagues: ${ }^{6}$ patient's age, smoking history, history of extrathoracic cancer, nodule diameter, upper lobe location, presence of nodule spicules, and FDG uptake on PET-CT.

\section{Statistical Analysis}

The normality distribution of variables used the Kolmogorov-Smirnov and Shapiro-Wilk tests. Numerical values that showed abnormal distribution were analyzed using median and interquartile applied to the Mann-Whitney test. The values that presented normal distribution were analyzed through the mean, standard deviation, and T Student's test. Dichotomous variables used Chi-square or Fisher's test. Statistical significance was considered as $p<0.05$ to all measurements. The accuracy of each model was assessed by calculating the area under the ROC curve (AUC). 


\section{Ehical Aspects}

The project was approved by the Comitê de Ética e Pesquisa (CEP) of the Escola Bahiana de Medicina e Saúde Pública, with the $n^{\circ}$ 1.905.164. Patient confidentiality was ensured.

\section{Results}

From a total of 135 patients with pulmonary nodules, 96 patients had a pathological diagnosis compatible with malignant neoplasia and 39 patients with benign disease (Table 1).

The patients with malignant neoplasia presented larger diameters lesions (average: $1.9 \mathrm{~cm}$ x 1.6 $\mathrm{cm}$ ) regarding CT characteristics of the nodule. The location of the nodules was predominantly in the upper lobes in all groups (Table 2).

The anatomopathological exam of patients with benign nodules showed a predominance of granulomatous disease, distributed as follows: tuberculoid granuloma $(28.2 \%)$, fungal granuloma (17.9\%) and unspecified $(25.9 \%)$. The predominant histology of malignant pulmonary nodules was adenocarcinoma $(68.8 \%)$, followed by carcinoid (12.5\%), and squamous carcinoma (9.4\%). Secondary implant represented $5.2 \%$ of this group (Graph 1).

The Swensen, Brock, and Herder models presented positive predictive value in high-risk patients, corresponding to $83.3 \%, 81.8 \%$, and $82.9 \%$, respectively (Table 3 ).

Patients considered at low-risk $(<5 \%)$ who underwent surgery and confirmed cancer by histology showed growth in prospective CT follow-up. The decision to do the intervention in the benign disease was mainly taken by the patients (Table 4).

From the total of 46 patients who underwent PET scan, there was no statistically significant difference in nodule size and SUV uptake value between groups; however, there was a tendency for higher uptake in the malignant group. Ten malignant nodules had no uptake; eight of them were considered histological adenocarcinoma, and 1 was considered carcinoid. Six nodules showed moderate uptake in the group of benign nodules, and five of them were an infectious granuloma.

Table 1. Demographic characteristics of patients with a pulmonary nodule.

\begin{tabular}{lccc}
\hline & $\begin{array}{c}\text { Benign } \\
\mathbf{n}=\mathbf{3 9}\end{array}$ & $\begin{array}{c}\text { Malignant } \\
\mathbf{n = 9 6}\end{array}$ & p Value \\
\hline Gender n (\%) & & & \\
Male & $13(25.5 \%)$ & $38(74.5 \%)$ & 0.497 \\
Female & $26(31.0 \%)$ & $58(69.0 \%)$ & \\
Age & & & \\
$\quad$ Median/IQ) & $52(23.0)$ & $65(11.0)$ & 0.003 \\
Smoking n (\%) & $35.9 \%$ & $61.5 \%$ & 0.007 \\
Yes, current & $0(0.0 \%)$ & $8(100.0 \%)$ & \\
Yes, a former smoker & $1(20.0 \%)$ & $44(80.0 \%)$ & \\
Yes, passive & $3(30.0 \%)$ & $7(70.0 \%)$ & \\
No & $25(40,3 \%)$ & $37(59.7 \%)$ & \\
History of previous neoplasia & & & \\
Yes, pulmonary & $0(0.0 \%)$ & $9(100.0 \%)$ & \\
Yes, extrapulmonary $>5$ years & $2(25.0 \%)$ & $6(75.0 \%)$ & \\
Yes, extrapulmonar $<$ 5 years & $7(31.8 \%)$ & $15(68.2 \%)$ & \\
No & $30(31.2 \%)$ & $66(68,8 \%)$ & \\
\hline
\end{tabular}


Table 2. Pulmonary nodule characteristics of selected patients.

\begin{tabular}{lcrc}
\hline & $\begin{array}{c}\text { Benign } \\
\mathbf{n = 3 9}\end{array}$ & $\begin{array}{c}\text { Malignant } \\
\mathbf{n = 9 6}\end{array}$ & p Value \\
\hline Size of a lesion at CPC (mean/DP) & $1.6(0.74)$ & $1.9(0.68)$ & 0.027 \\
Lesion ground glass n(\%) & & & 0.359 \\
100\% ground glass & $1.0(12.5 \%)$ & $7.0(87.5 \%)$ & \\
With solid component $<50 \%$ & $4.0(19.0 \%)$ & $17.0(81.0 \%)$ & \\
With solid component $>50 \%$ & $6.0(42.9 \%)$ & $8.0(57.1 \%)$ & \\
100\% solid & $28.0(39.4 \%)$ & $64.0(69.6 \%)$ & 0.398 \\
Location n (\%) & & & \\
$\quad$ Upper lobes & $18.0(25.7 \%)$ & $52.0(74.3 \%)$ & \\
Others & $21.0(32.3 \%)$ & $44.0(67.7 \%)$ & 0.295 \\
Lobes n (\%) & & & \\
Superior - Right & $13.0(31.7 \%)$ & $28.0(68.3 \%)$ & \\
Medium & $4.0(33.3 \%)$ & $8.0(66.7 \%)$ & \\
Inferior - Right & $12.0(42.8 \%)$ & $16.0(57.2 \%)$ & \\
Superior - Left & $5.0(17.2 \%)$ & $24.0(82.8 \%)$ & \\
Inferior - Left & $5.0(20.8 \%)$ & $19.0(79.2 \%)$ & \\
Right bronchus & $0.0(0.0 \%)$ & $1.0(100.0 \%)$ & \multirow{2}{*}{0.986} \\
Spiculated n (\%) & & & \\
$\quad$ Yes & $22.0(29.0 \%)$ & $54.0(71.0 \%)$ & \\
No & $17.0(28.8 \%)$ & $42.0(71.2 \%)$ & \\
\hline
\end{tabular}

Graph 1. Proportional distribution of patients with pulmonary nodule according to pathological anatomy.

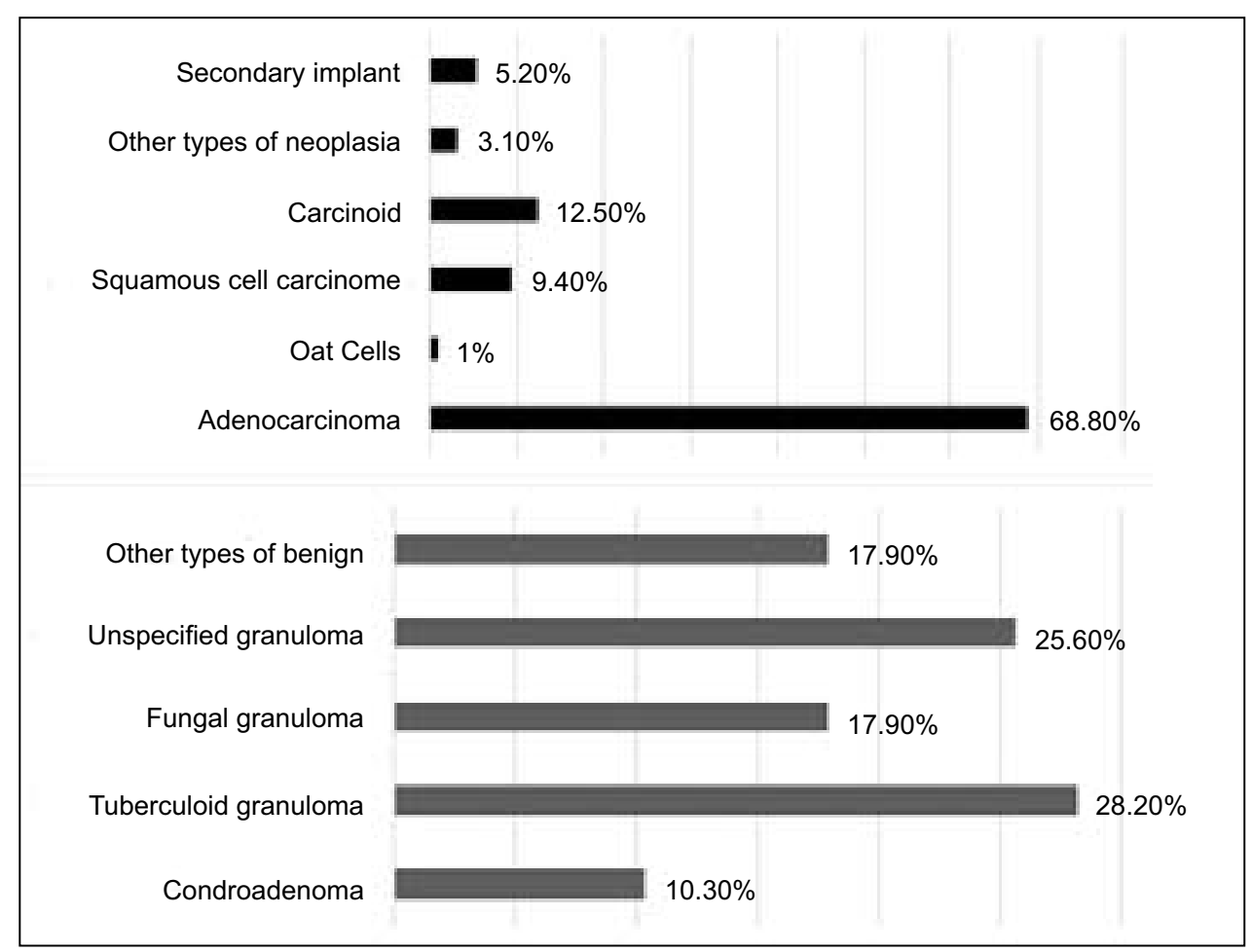

www.revistacientifica.hospitalsantaizabel.org.br 
Table 3. Comparison between the risk for malignancy predicted by the 3 models and the number of cases of malignancy.*

\begin{tabular}{lccc}
\hline Model & $\begin{array}{c}\text { Median of individual } \\
\text { scores (category) } \\
\mathbf{n}=\mathbf{1 3 5}\end{array}$ & $\begin{array}{c}\text { Distribution of } \\
\text { total patients (category) } \\
\mathbf{n = 1 3 5}\end{array}$ & $\begin{array}{c}\text { The proportion } \\
\text { of confirmed cases } \\
\text { of malignancy } \\
\text { (category) } \\
\mathbf{n}=\mathbf{9 6}\end{array}$ \\
\hline Swensen & & & \\
$\quad$ High-risk & 79.6 & 30 & $25.0(83.3 \%)$ \\
$\quad$ Medium-risk & 27.4 & 91 & $66.0(72.5 \%)$ \\
Low-risk & 3.4 & 14 & $6.0(42.8 \%)$ \\
Brock & 70.0 & & $8.0(88.8 \%)$ \\
$\quad$ High-risk & 27.7 & 112 & $81.0(72.3 \%)$ \\
$\quad$ Medium-risk & 3.3 & 14 & $7.0(50.0 \%$ \\
$\quad$ Low-risk & & & \\
Herder & 87.2 & 41 & $34.0(82.9 \%)$ \\
$\quad$ High-risk & 26.9 & 75 & $52.0(69.3 \%)$ \\
$\quad$ Medium-risk & 3.0 & 19 & $10.0(52.6 \%)$ \\
$\quad$ Low-risk & & & \\
\hline
\end{tabular}

$*$ High-risk $=>65 \%$, Medium-risk $=5 \%-65 \%$, Low-risk $<5 \%$.

Graph 2. Accuracy comparison of different regressions in patients with the single pulmonary nodule.

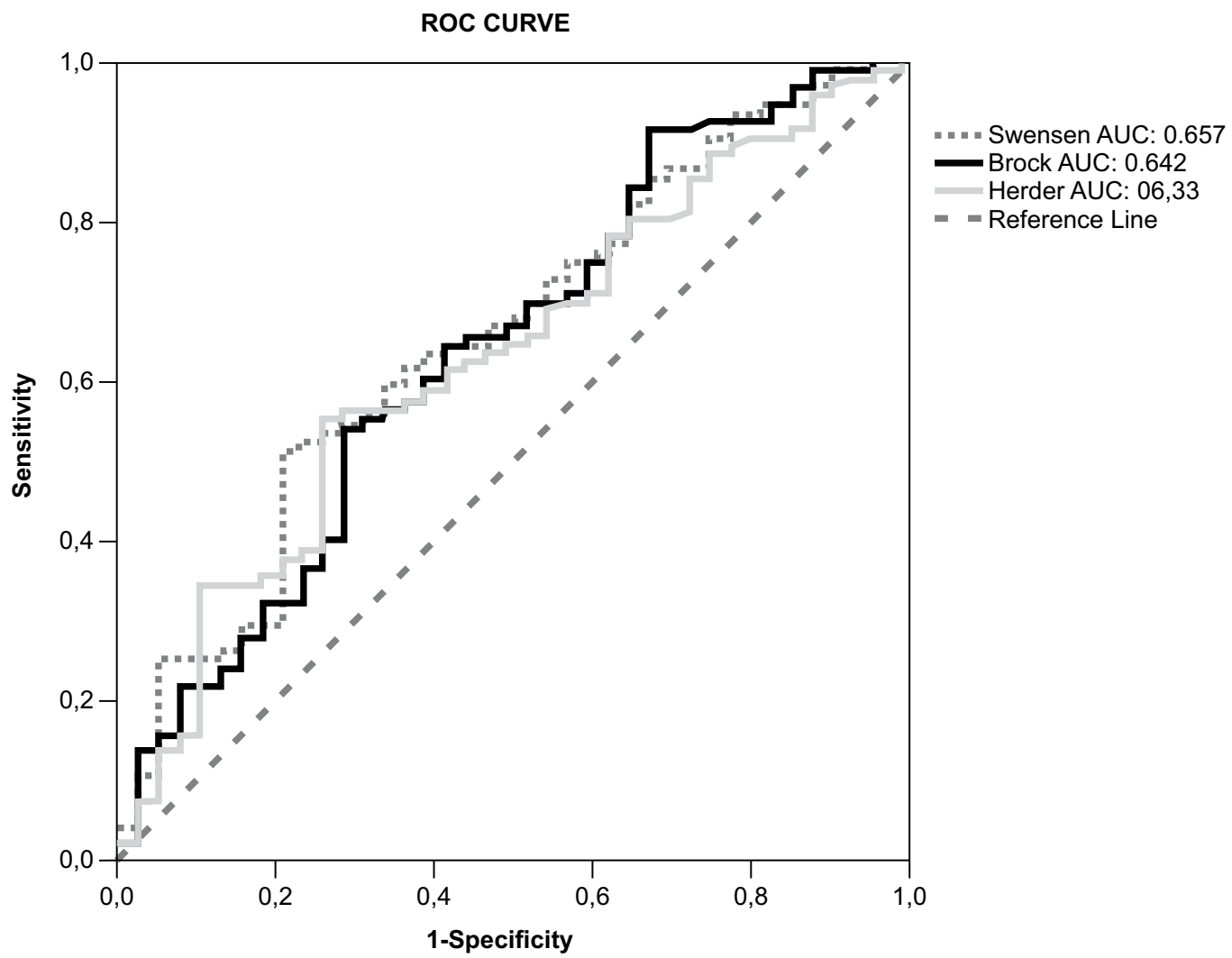


Table 4. Comparison of the different reasons why low-risk patients $(<5 \%)$ underwent surgery in different models.

\begin{tabular}{lll}
\hline Model & Benign & Malignant \\
\hline Swensen & n: 8 & n: 6 \\
n total: 14 & Patient choice: $5(62.5 \%) ; \uparrow$ CT injury: & $\uparrow$ CT injury: $4(66.7 \%)$ \\
& $1(12.5 \%)$ Previous neoplasia: $1(12.5 \%)$ & Prior Diagnosis: $1(16.6 \%)$ \\
& GGO Persistence in CT Control: $1(12.5 \%)$ & GGO Persistence in CT \\
Brock & n: 7 & Control: $1(16.6 \%)$ \\
n total: 14 & Patient choice: $5(71.4 \%)$ & n: 7 \\
& $\uparrow$ CT injury: $1(14.3 \%)$ & $\uparrow$ CT injury: $5(71.4 \%)$ \\
& Previous neoplasia: $1(14.3 \%)$ & Sequential procedure with \\
& & Thyroid surgery: $1(14.3 \%)$ \\
Herder & n: 9 & Patient choice: $1(14.3 \%)$ \\
n total: 19 & Patient choice: $6(66.6 \%)$ & n: 10 \\
& GGO Persistence in CT Control: $1(11.1 \%)$ & $\uparrow$ CT injury: $5(50 \%)$ \\
& Previous neoplasia: $1(11.0 \%)$ & SUV didn’t pick up, \\
& $\uparrow$ CT injury: $1(11.0 \%)$ & high brock: $1(10.0 \%)$ \\
& & GGO Persistence in CT \\
& & Control: $2(20.0 \%)$ \\
& & Prior Diagnosis: $2(20.0 \%)$ \\
\hline
\end{tabular}

GGO: Ground-glass opacity.

\section{Discussion}

The diagnosis of pulmonary nodule is a relatively frequent finding from imaging exams. According to Tan and colleagues, ${ }^{10}$ over than 150,000 patients per year seek medical care after being diagnosed with a pulmonary nodule in the USA, found on both chest radiography and chest computed tomography. Despite being a common finding, approaching this nodule is still a significant challenge for specialists due to the absence of symptoms, unspecific morphological characteristics, and the probability of malignancy. More lung nodules have been diagnosed because of the growing number of lung cancer tomographic screening programs and the more frequent use of coronary tomography scans. Thus, the prediction models of malignancy returned to the scientific discussions. However, validated models in the literature do not address some of the critical clinical and radiological factors in the clinical decision of suspected malignancy. This study was designed to evaluate the retrospective impact of three malignancy pretest calculations on patients who had a clinical indication for resection.

Three mathematical models were evaluated to predict malignancy in pulmonary nodules. Analyzing the results obtained using the Swensen (AUC 0.657, IC 95\% 0.556 - 0.758), Brock (AUC 0.642, IC 95\% $0.537-0.747$ ) and Herder (0.633, IC 95\% $0.531-0.735)$ models in the present study, it was possible to notice that AUC has a poor performance when compared to studies that validated these models. Al-Ameri

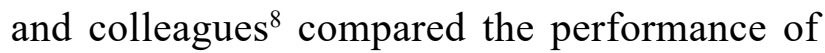
four models and obtained the following results: Swensen (AUC 0.895, IC 95\% 0.850 - 0.939), Brock (AUC 0.902, IC 95\% 0.856 - 0.948), Herder (AUC 0.924, IC 95\% 0.875-0.974) and Gould (AUC 0.735, IC 95\% 0.670 - 0.800). The good results obtained by the Swensen model and the better ones obtained by the Brock and Herder models were probably achieved because it is a (prospective) cohort study, revealing that clinical selection makes the accuracy of the three 
models lower in the overall assessment by AUC when included other factors to the judgment.

When analyzing the models by risk category (low, moderate, and high), they were useful in predicting the potential of malignancy of the high-risk nodule. However, it underestimated the intermediate-risk (5\%-65\%) and low-risk ( $<5 \%)$. A multidisciplinary team made the recommendation for surgery following the pretest calculations and the characteristics not measured by the models, such as: previous histological diagnosis, CT lesion growth, morphological alteration, history of previous neoplasia, persistence of nodules with standard of ground glass, which may not have FDG uptake on PET scan, and other radiological features such as nodule to bronchial relationship, presence of bronchial dilation, nodule calcification pattern, and pleural umbilication.

The instability of a solid nodule or its growth on imaging exams is considered an indicator of malignancy. Besides the nodule size or volume, the change in morphology may also suggest malignancy, even in the absence of diameter increase as described by Bartholmai and colleagues. ${ }^{11,12} \mathrm{~A}$ low-attenuating nodule has a very close tomographic correlation with adenocarcinomas of the lepidic pattern. These cases frequently have pretest calculations $<5 \%$ risk (low-risk). However, it is common that they turn-out to have a surgical indication. The sign of adjacent bronchial retraction also suggests malignancy. ${ }^{13,14}$ These are some of the factors described in the literature that can be added to the information provided by the pretest calculations in a multidisciplinary decision.

In this study, three of the clinical and radiographic characteristics related to the pulmonary nodules showed statistical significance when associated with malignancy: older age of the patient, smoking and larger diameter of the pulmonary nodule. In agreement with the literature, the highest incidence of lung cancer can be found in the group of people from 60 to 70 years old, ${ }^{15}$ which validates the median of 65 years calculated in the study.
Doll and Hill ${ }^{16}$ showed that smoking is closely linked to the onset of lung cancer. Although the association between exposure to tobacco and the increase of lung cancer incidence is well documented, it tends to be lower for adenocarcinoma cases. ${ }^{9}$ Our study observed that $38.5 \%$ of the total number of patients with malignant nodules had never been smokers, which may be justified by the high prevalence of adenocarcinoma (68.8\%).

As well as in the prediction models already validated, nodule size is an independent predictor of malignancy. In this study, malignant nodules had an average size of $1.9 \mathrm{~cm}$, while the average size of benign nodules was $1.6 \mathrm{~cm}$.

However, this study has limitations such as the small number of the global sample, as well as the subgroup of patients undergoing PET-CT, which made impossible to have a more reliable statistical analysis of the model developed by Herder.

\section{Conclusion}

The increasing diagnosis of pulmonary nodules, quantitative models have been extensively reevaluated to understand the possible impact they may have on patients management. In this study, none of the three quantitative models analyzed obtained an acceptable accuracy in the methodology and the specific population (AUC> $0.7)$.

Three of the clinical and radiographic characteristics related to the nodule showed statistical significance when associated with malignancy: older age of the patient, smoking history, and larger diameter of the nodule on tomography.

The three models performed well in characterizing the probability of malignancy of high-risk nodules. However, the models underestimated the nodules with intermediate or low-risk, so they should be used with caution in this context. Characteristics such as CT lesion growth, the persistence of nodules with a lepidic pattern, morphology, and the relationship between 
nodule, bronchus, and pleura, may be relevant in predicting malignancy in patients with pulmonary nodules referred for surgeon evaluation. So, they may reduce the overall accuracy of the pretest models, due to not inclusion of this population in the prediction models.

Regarding the current clinical knowledge of the presented factors is this manuscript, further prospective studies need to be performed to assess the individual impact of each of these factors on the prediction of malignancy of a lung nodules.

\section{References}

1. Manuscript A. A clinical model to estimate the pretest probability of lung cancer in patients with solitary pulmonary nodules. NIH Public Access. 2010;131(2):383-8.

2. Swensen SJ, Silverstein MD, Ilstrup DM, Schleck $\mathrm{CD}$, Edell ES. The probability of malignancy in solitary pulmonary nodules. Application to small radiologically indeterminate nodules. Arch Intern Med. 1997;157(8):849-55.

3. Schultz EM, Sanders GD, Trotter PR, Jr EFP, Gerard A, Owens DK, et al. Validation of Two Models to Estimate the Probability of Malignancy in Patients with Solitary Pulmonary Nodules. 2010;63(4):335-41.

4. Hill C. Lung cancer screening with low-dose computed tomography for primary care providers. 2015;73(4):389400.

5. McWilliams A, Tammemagi MC, Mayo JR, Roberts H, Liu G, Soghrati K, et al. Probability of cancer in pulmonary nodules detected on first screening CT. N Engl J Med [Internet]. 2013;369(10):910-9. Available from: http://www.pubmedcentral.nih.gov/articlerender. fcgi? artid $=3951177 \&$ tool $=$ pmcentrez\&rendertype $=$ abs tract.

6. Herder G, Tinteren H, Golding RPM, Kostense PJ, Comans EF, Smit EFP, Hoekstra OSP. Clinical prediction model to characterize pulmonary nodules validation and added value of 18-Fluorodeoxyglucose positron emission tomography. Chest. 2005;2490-6.

7. CBC M, JAJ P, DF D, ASC CJ, IL S, LEV L. Analysis and validation of probabilistic models for predicting malignancy in solitary pulmonary nodules in a population in Brazil. J Bras Pneumol. 2012;38(5):559-65.
8. Al-Ameri A, Malhotra P, Thygesen H, Plant PK, Vaidyanathan $\mathrm{S}$, Karthik $\mathrm{S}$, et al. Risk of malignancy in pulmonary nodules: A validation study of fourprediction models. Lung Cancer [Internet]. 2015;2-5. Available from: http://dx.doi.org/10.1016/j.lungcan.2015.03.018

9. Gould MK, Donington J, Lynch WRM, Mazzone PJ, Midthun DE, Naidich DP, Wiener RS. Evaluation of individuals with pulmonary nodules: when is it lung cancer? Diagnosis and Management of Lung Cancer, $3^{\text {rd }}$ ed: American College of Chest Physicians. 2013;(May):93-120.

10. Tan BB, Flaherty KR, Kazerooni E a, Mark D. The solitary pulmonary nodule. Chest. 2003;123:89S-96S.

11. Niehaus R, Raicu DS, Furst J. Toward understanding the size dependence of shape features for predicting spiculation in lung nodules for computer-aided diagnosis. 2015;704-17.

12. Bartholmai BJ, Koo CW, Johnson GB, White DB, Raghunath SM, Rajagopalan S, et al. Pulmonary nodule characterization, including computer analysis and quantitative features. 2015;30(2):139-56.

13. Silva DR, Gazzana MB. Nódulo pulmonar solitário. Rev Bras Clinica Medica [Internet]. 2009;7(51):132-9. Available from: http://files.bvs.br/upload/S/16791010/2009/v7n2/a010.pdf.

14. Khan A, Al-Jahdali H, Irion K, Arabi M, Koteyar S. Solitary pulmonary nodule: A diagnostic algorithm in the light of current imaging technique. Avicenna J Med [Internet]. 2011;1(2):39. Available from: http://www. avicennajmed.com/text.asp?2011/1/2/39/90915.

15. Freitas ED De. Aspectos epidemiológicos do câncer de pulmão em uma instituição privada. Rev Bras Oncol Clínica. 2010; 7:55-9.

16. Doll R, Hill AB. Smoking and carcinoma of the lung: Preliminary report. Br Med J. 1950;77(1):84-93.

17. Burns DM. Primary prevention, smoking, and smoking cessation: implications for future trends in lung cancer prevention. Am Cancer Soc. 2000;89(11 Suppl):2506-9.

18. Zamboni M. Epidemiologia do câncer do pulmão. J Pneumol. 2002;28(1):41-7.

19.Rafanan AL, Ceniza SV, Canete MT. Two commonly used prediction models (Mayo and VA) to estimate the probability of malignancy in patients with solitary pulmonary nodules are not applicable in a country with a high prevalence of tuberculosis. Chest. 2010;138(4_MeetingAbstracts):250A 250A. doi: 10.1378/chest.10657.

20. Ost D, Fein A, Feinsilver S. The solitary pulmonary nodule. N Engl J Med. 2003;123:89S-96S. 